\title{
Türkçenin Yabancı Dil Olarak Öğretiminde Çevrim İçi İş Birlikli Görev Tasarlama
}

\author{
Kayhan İnan* \\ Makale Geliş Tarihi: 25/12/2020 \\ Makale Kabul Tarihi: 27/01/2021 \\ DOI: $10.35675 /$ befdergi. 846707
}

$\ddot{O}_{\boldsymbol{z}}$

Bu makalede çevrim içi ortamda uygulanabilecek iş birlikli görevler üzerinde durulmuş ve bazı görev önerilerine yer verilmiştir. Belirlenen ölçütlere göre tasarlanan görevler ile ögrenicilerin birbirleri ile konuşmalarl, birbirlerini dinlemeleri ve birlikte yazmaları amaçlanmıştır. Hedef dilde üretilen iş birlikli diyalogların ögrenicilerin birbirlerinin dil üretimlerini denetlemelerine ve desteklemelerine yardımcı olacağ öngörülmüş̧ür. Makale kapsamında önerilen etkinliklerde öğrenicilerin günlük internet kullanımlarından aşina oldukları konular için hedef dili kullanacakları ve bunu yaparken diğer öğreniciler ile içerik ve yapı üzerinde müzakere edecekleri düşünülmüştür. Dilin konuşulduğu ülkeye ve o ülkenin kültürüne ilişskin bilgiler de çevrim içi iş birlikli görevler üzerinden ögrenicilere sunulabilir. Ayrıca öğreticiler öğrenicilerin yeterli dijital okuryazarlı̆̆a sahip olmaların da göz önünde bulundurmalıdir.

Anahtar Kelimeler: Çevrim içi dil öğretimi, iş birlikli diyalog, iş birlikli görevler, Türkçenin yabancı dil olarak öğretimi

\section{Online Collaborative Task Design in Teaching Turkish as a Foreign Language}

\begin{abstract}
In this article, as one of these quests, collaborative tasks that can be applied online are emphasized and some task suggestions are given. It is aimed for learners to talk, listen to each other, and write together with the tasks. It was predicted that collaborative dialogues will help learners' support each other's language production. In the activities suggested within the article's scope it was thought that the learners will use the target language for the topics they are familiar with from their daily internet use, and while doing this, they will negotiate with other learners on the content and structure. Collaborative tasks can achieve the goals set by the instructor. Information about the country where the language is spoken, and the culture of that country can be presented to learners through online collaborative tasks. Tutors also should consider that learners must have sufficient digital literacy.
\end{abstract}

Keywords: Collaborative dialogues, collaborative tasks, online language teaching, teaching Turkish as a foreign language

\section{Giriş}

Geleneksel sınıf içi dil öğretim programları 2020 yılı başından itibaren görülmeye başlanan ve etkisini dünyanın her yerinde hissettiren küresel salgın nedeniyle kesintiye uğrama ve bir ölçüde tamamen durma tehlikesi ile karşı karşıya kalmıştır. Bunun üstesinden gelmek için öğretim hızlı bir şekilde çevrim içi ortama aktarılmış

*Amasya Üniversitesi, Amasya, Türkiye, kayhan.inan@amasya.edu.tr, ORCID: 0000-0002-7438-0742 (D) 
ve akademik yarıyılın bir şekilde tamamlanması sağlanmıştır. Türkçenin ağırlıkla yüz yüze eğitim üzerinden öğretilmesi ve öğretim yapan kurumların eğitim ve çalışma düzenlerini buna göre tasarlamış olmaları öncelikle kurumların kendilerini gözden geçirmelerini gerektirmiştir. Uzaktan ve çevrim içi dil öğretiminin kendine özgü bir pedagojisinin olması ve öğreticilerin buna yönelik bilgi ve tecrübe eksiklikleri başta bilişim becerilerinin kullanımı açısından problemler doğurmuştur. Öğreticilerin yüz yüze öğretimde kullandıkları yöntemlerin çevrim içi ortamda öğreniciyi etkin kılma, öğreniciler arasında etkileşim sağlama ve zaman yönetimi açısından sorunlar doğurduğu görülmüştür. Benzer şekilde öğrenicilerin de dil öğrenmeye yönelik alışkanlıklarının değişmesi onlar için zorlayıcı olmuştur. Sınıf içi etkileşimden mahrum olmak ve etkin katılım gereken uygulamaların eksikliği onları edilgin bir konuma itmiştir.

Süreçte yaşananlar dikkatleri daha önce çeşitli üniversiteler ve Yunus Emre Enstitüsünün yürüttüğü uzaktan Türkçe öğretimi programlarına çekmiş ve yeni girişimlerin önünü açmıştır. Türkçe öğreten kurumlarda yüz yüze eğitim yapılamaması Türkçenin belki de tarihte ilk defa bu kadar yoğun bir şekilde uzaktan ve çevrim içi uygulamalar üzerinden öğretilmesini sağlamıştır. Aynı zamanda özellikle sosyal medya araçları üzerinden öğretici ve öğrenicilere yönelik çevrim içi seminerler ve sertifika programları düzenlenmiştir. Ancak bu durum yoğun bilgi sağanağına maruz kalan öğretici ve öğrenicilerin kendilerini buldukları bu yeni düzende onlara sağlanan bilgi ve olanaklardan ne derece verim aldıkları tartışmalı hâle gelmiştir. Buna karşın hedef dile ilişkin girdi sağlamada çevrim içi dil öğretim hem öğreticiler hem de öğreniciler tarafindan tecrübe edilmiştir. Bu süreçte YouTube videolarının, Instagram canlı yayınlarının, Netflix film ve dizilerinin, ses kayıtlarının birer "girdi sağlayıcıları" (Lempinen, 2020; Wong, 2020) olarak geniş kitleler tarafından kullanıldığı görülmüştür.

$\mathrm{Bu}$ gelişmeler çevrim içi ortamda dil girdilerini ve bunun yönetimini öne çıkarmaktadır. Ancak dil öğretiminde etkileşim ve dönüt de hedef dilin gelişimi açısından önemlidir (Long, 1985; Bialystok, 1978; Krashen, 1987). Öğreticilerin girdi kaynaklarını dil öğretimini destekleyecek, öğrenicilerin birbirleri ile etkileşimlerini artıracak ve onlara nitelikli dönütler sağlayacak şekilde düzenlemeleri gerekmektedir. Yüz yüze eğitimde olduğu gibi çevrim içi ortamda da hedef dile ait girdilerin işlenip çıtıya dönüşmesi için teknolojinin izin verdiği ölçüde taraflar arasında etkileşime olanak sağlanmalıdır. Bu etkileşim düzeyinin artırılmasında iş birlikli öğrenme yaklaşımına göre tasarlanmış görevler, öğreticilerin değerlendirebileceği seçenekler arasındadır.

Dil öğretiminde iş birliğini temel alan yaklaşımlar öncelikle öğrenicilerin bir grup içerisinde birbirinden öğrenmesini amaçlamaktadır. Grup ile beraber öğreticilerin de süreçte rolü bulunmaktadır. Birlikte çalışmanın yanında iletişsim kurmak da hedefler arasındadır (Larsen Freeman, 2003). İş birlikli öğrenme yaklaşımının savunucuları, öğrenmede sosyal etkileşimin merkezi rolünü vurgulayan gelişimsel psikolog Lev Vygotsky'nin çalışmalarından büyük ölçüde yararlanır. Öğrenmenin sosyal olarak konumlandırılmış ve gösterge bilim aracılı bir süreç olduğunu savunan Vygotsky (1998) öne sürdüğü yakınsal gelişim alanı içerisinde öğrenmenin ilk olarak kişilerarası düzeyde, ardından bireysel düzeyde 
gerçekleştiğini savunur. Yakınsal iletişim alanı içerisinde kişilerin semiyotik araç olarak dili kullandığına işaret eder.

İş birlikli öğrenme, farklı etkileşim türleri yoluyla hedef dil uygulamalarının sıklığı ve çeşitliliğini artırması, etkileşim temelinde dilin edinilmesini kolaylaştırması, dili içerik tabanlı eğitimle bütünleştirme firsatı barındırması, çok çeşitli müfredat materyallerini sürece dâhil etmesi, sadece öğreticilerin değil öğrenicilerin de birbirleri için kaynak görevi görmesi bakımından önemlidir (Richards \& Rogers, 2002). İkinci bir dilin edinilmesinin maruz kalınan girdi miktarına bağlı olduğunu öne süren Krashen (1987) öğreniciler arasındaki konuşma ve dinlemeye dayalı etkinliklerin dile ilişkin anlamlı girdiler sağlamada önemli olduğuna dikkat çeker. Buna göre akranlar arasında konuşma ve konuşulanı dinlemeye dayalı bir etkileşim, öğrenicilerin karşılıklı olarak anlam üzerinde müzakere etmeleri için firsat yaratmaktadır. Anlamın müzakere edilmesi anlaşılır girdinin alınmasını ve işlenerek çıtıya dönüşmesini sağlamaya yardımcı olur. Sosyokültürel yaklaşım çerçevesinde Swain (2000), çıktıların öğrenmedeki rolünü açıklarken iş birlikli diyalog kavramını ortaya atmıştır. İş birlikli dil öğretimi yaklaşımı içerisinde değerlendirilen iş birlikli diyalog, herhangi bir konuda dil öğrenicilerinin problem çözme ve bilgi oluşturma ile meşgul oldukları diyalog şeklinde tanımlanmaktadır. Öğrenicilerin birbirleri ile etkileşim sırasında ürettikleri bu diyaloglar onların birbirlerinden dile ilişkin yeni bilgiler öğrenmelerini ve bildiklerini tekrar etmelerini sağlar. Diyaloglar aracılığı ile öğreniciler konuşma ve dinleme yolu ile anlamı zihinlerinde yeniden yapılandırır. Böylece iş birlikli diyalog içerisinde öğreniciler amaçlanan anlamı nasıl daha iyi şekilde ifade edeceklerini bulmak için sorular sorarak, tartışarak ve yardımlaşarak birbirlerini destekleyici bir iskele inşa ederler.

Destekleyici iskele, Tavakkoli (2012) tarafindan öğrenicinin öğretim sürecinde tamamlaması gereken etkinlik ve görevlerde yetkinliğini aşan durumlar için diğer akranlarından destek alması olarak tanımlanmaktadır. Bu destek daha çok bir diyalog içerisinde karşılıklı konuşma ve soru-cevap şeklinde olabilir. Soruyu basitleştirme, cümlenin bir bölümünü kurarak öğrenicinin tamamlamasını sağlama, daha yavaş konuşma, görseller kullanma destekleyici iskele stratejileri içinde yer almaktadır. Gibbons'a (2015) göre destekleyici iskele, yardımdan çok, öğrenicinin daha sonraki aşamada benzer bir durumla karşılaştığında ne yapması gerektiğini göstermektir. Riazi ve Rezaii (2010) bu noktada öğretici kadar akranların kılavuzluğunun da hedefe ulaşmak üzere karar almada ve problem çözmede yararlı olduğu belirtir. Akranlar arası gerçekleştirilen destekleyici bir iş birlikli diyaloğun dil öğrenimi için Krashen'in (1987) işaret ettiği anlamlı girdilerin sağlanmasında bir kaynak olduğunu gösteren araştırmalar bulunmaktadır (Swain \& Lapkin, 2002; Watanabe \& Swain, 2007). Bu araştırmalar iş birlikli diyalog içerisinde öğrenicilerin ürettikleri dil hakkında konuştuklarına, birbirlerinin dil kullanımlarını sorguladıklarına, kendilerini ve başkalarını düzelttiklerine işaret etmektedir.

$\mathrm{Bu}$ araştırmalar 1şığında öğrenicilerin gerek akranları gerek öğreticileri ile anlamlı ve destekleyici bir faaliyetin parçası olmalarında iş birlikli görevlerin kullanılabileceği düşünülmektedir. Swain (2000) iş birlikli görevleri birlikte çalışma, ürün ortaya koyma, hedef dildeki biçim ve içerik üzerinde düşünmeyi başlatan bir 
adım olarak nitelendirmektedir. Bu çerçevede iş birlikli görevler, öğrenicileri ortaya çıkacak ürünün üretimi üzerinde ortak bir sorumluluk ve sahiplenme duygusu geliştirmelerini teşvik edecektir.

İş birlikli dil öğretimi ile ilgili araştırmalara bakıldığında bunların ağırlıkla Türkçenin dişındaki dillerin öğretimine yönelik olarak yürütüldüğü görülmektedir. Konuyu Türkçenin yabancı dil olarak öğretimi açısından inceleyen araştırmalar az da olsa mevcuttur. Varışoğlu (2013) ve Ekinci (2018) yazma becerisinin geliştirilmesinde iş birlikli dil öğretiminin kullanımını araştırmıştır. Bölükbaş (2014) Jigsaw-IV tekniğinin temel zamanların öğretimindeki etkisini araştırmıştır. Sözü edilen araştırmalar yüz yüze dil öğretimine yönelik olsa da Başkaya ve Tursunovic'in (2017) makalesi çevrim içi iş birlikli dil öğretiminde kullanılabilecek bir araç olarak Padlet uygulamasını tanıtması açısından diğerlerinden ayrılır. Çevrim içi ortam ve iş birlikli görevler bağlamında Türkçe öğretimine yönelik yeni koşulları göz önünde bulunduran bir çalışmanın da yararlı olacağı düşünülmektedir. $\mathrm{Bu}$ makalede de çevrim içi dil öğretiminde iş birlikli görevlerin kullanılmasına ilişkin bilgilere ve etkinlik önerilerine yer verilmesi amaçlanmıştır.

\section{İş Birlikli Dil Öğretiminde Görevler}

Öğretici ve öğrenicinin katılımı ile ders içinde ve dışında yer verilecek görevleri, Nunan (1989) dil öğrenme sürecini ilerletmek için öğrenicilere dil sınıfında yapmaları için verilen her türlü etkinlik olarak tanımlamaktadır. Görevler, öğrenicilerin amaca yönelik olarak etkileşim kurma ve müzakere etme süreçlerini işletmesi ile dilin kazanılmasını sağlar. Bu bakımdan görevler iki veya daha fazla katılımcı arasında anlamlı bir etkileşimin gerçekleştiği bir zemin sunmaktadır. Böylece öğreniciler kelime ve cümlelerin yapı ve anlamları üzerinden tartışarak dilin işleyişini kavrar. Cook'a (2001) göre öğretimin göreve dayalı planlanması derslere geniş katılım ve öğretici açısından daha fazla rehberlik etme olanağı yaratarak hedef dilde iletişim becerisini geliştirir.

Ellis (2003), doğru ve uygun öğrenme içeriğinin anlamlı bir şekilde aktarılıp aktarılmadığını değerlendirmek için görevlerde dilin pragmatik boyutları üzerinde durur. $\mathrm{Bu}$ nedenle görevler anlamlı üretimde bulunmayı öncelemelidir. Bir görev, dilin gerçek yaşamda kullanıldığı şekline doğrudan veya dolaylı olarak benzerlik gösteren sonuçlar üretmelidir. Görevler diğer dil etkinlikleri gibi becerilerin birlikte kullanımını ve çeşitli bilişsel stratejileri içerebilir.

Görevlerin türü, kapsamı, planlanması ve uygulanmasında çeşitli modeller ortaya konulmuştur. Bu noktada Ellis (2003) görevlerin genel çerçevesini tür, önem, dilsel ve bilişsel karmaşıklık, öğreticiye bağlı etkenler ve öğreniciye bağlı etkenler başlıkları ile çizmiştir. Bu çerçeveye göre görevler rol yapma ve canlandırmadan oyun ve bulmacalara kadar günlük yaşam ile ilgili farklı türlerde olabilir. Görevler dil öğretiminin tamamını veya bir kısmını kapsayacak şekilde uygulanabilir. Aynı zamanda görevlerin içeriği öğreniciler için dil bilimsel ve bilişsel boyutları kapsayacak şekilde bütünleşik bir organizasyona sahip olabilir. Görevin dil bilimsel karmaşıklığı öğrenicinin dile ilişkin bilgileri ve dilin kullanımına yönelik yeterliklerini kullanmasını gerektirirken, görevin bilişsel karmaşıklığı öğrenicinin diğer alanlardaki bilişsel yeterliklerini de kullanmasını gerektirmektedir. Öğreticiye 
bağlı etkenler görevde öğreticinin rolünü ve sağlayacağı desteği içerirken öğreniciye bağlı etkenler ise bireysel özellikleri ve öğrenme stilleri ile ilgilidir. Benimsenen yaklaşım ve belirlenen hedefler görevin türüne karar verilmesinde etkiliyken öğreniciye bağlı etkenler ile görevin karmaşıklığı görevin uygulanabilirliğinde söz sahibidir.

İş birlikli görevlerde benimsenen genel yaklaşım, küçük gruplar hâlinde örgütlenen öğrenicilerin öğrenme gerçekleşene kadar birlikte çalışması şeklindedir (Çubukçu, 2012). Bu bağlamda teknolojinin sunduğu olanaklar dil öğretiminde iş birlikli görevlerin çevrim içi ortama aktarılarak yürütülebileceğini akla getirmektedir. Gonzales Lloret (2020) teknoloji aracılı iş birlikli görevlerin çevrim içi öğrenmenin önemli bir bileşeni olan grup etkileşimini kolaylaştıracak ve öğreniciler arasında bir topluluk hissi oluşturmaya yardımcı olacak sağlam bir tasarım çerçevesi sağlayacağına işaret etmektedir.

\section{Teknoloji Temelli İş Birlikli Görev Ölçütleri}

Chapelle (2001) 21. yüzyılda ikinci dil öğretimi ve öğrenimi ile ilgilenen herkesin, dil edinimine yönelik teknoloji temelli görevlerin doğasını kavraması gerektiğine işaret etmektedir. Chapelle, öğreticileri bilişim teknolojilerini nasıl daha etkili kullanacaklarını ve bundan nasıl üst düzey verimin alacaklarını düşünmeye davet etmektedir. Ona göre öğretici ve öğreniciler daha fazla teknolojiden yararlandıkça, teknoloji aracılı görevlerin geliştirilmesi ve kullanılmasında daha fazla seçenek üretilecektir. Gruba (2004) ilk dönemde çevrim içi öğretimde kullanılan görevlerin beklenen etkiyi vermediğine dikkat çekerek, yeni şartlara uygun görev tasarlama ölçütlerinin belirlenmesi gerektiğine değinmektedir.

Chapelle'in (2001) bilgisayar destekli dil öğretimi için belirlediği ölçütleri çevrim içi video konferans görevlerine uyarlayan Wang (2007) görevlerin uygulanabilirlik, dil öğretimi potansiyeli içerme, öğreniciye uygunluk, diş dünya ile uyumluluk ve olumlu duyuşsal etki başlıklarına göre tasarlanması gerektiğini belirtmiştir. Doughty ve Long (2003), etkinlik, girdi, öğrenme süreci ve öğrenici başlıkları altında ona yakın ölçüt belirlemiştir. Etkinlik başlığı altında görevlerin etkinlikler içinde yer alması ve öğrenmeyi desteklenmesi ele alınmaktadır. Girdi başlığı altında görevin özgün ve anlamlı girdi içermesi üzerinde durulmuştur. Öğrenme süreci en geniş kapsama sahip başlıktır. Bu başlık görevlerin işlenme sürecinde dönüt ve düzeltmeyi, yapıya odaklanmayı ve iş birlikli öğrenmenin desteklenmesini içermektedir. Öğrenici başlı̆̆ı ise öğrenicilerin özellik ve ihtiyaçları ile ilgilidir.

Hampel (2010), Ellis'in (2003) belirlediği görev türü, görevin önemi, dil bilimsel ve bilişsel karmaşıklık, öğretici ve öğrenici ölçütlerine Oxford'un (2006) görev ölçütlerinde yer alan hedef, girdi, öğretim koşulları, yöntem ve beklenen çıktılar başlıklarını ekleyerek çevrim içi öğretimde kullanılması düşünülen görevlerin hazırlanma ve işlenme süreçlerine ilişkin kapsamlı bir liste hazırlamıştır. Hampel, özellikle Oxford'un belirlediği görev ölçütlerinden girdi ve çıktı kavramlarının üzerinde durmuştur. Bunun yanında girdilerin çıktıya dönüşmesinde öğretim koşullarının etkili olabileceğine, bunun da etkileşim, bilgilerin paylaşılması ve iş birliği ile sağlanabileceğine dikkat çekmektedir. 
Gonzales Lloret (2020) ise çevrim içi dil öğretiminde yararlanılacak görevlerin tesadüfi öğrenmeler de içerecek şekilde anlama odaklanması, iletişimi zorunlu kılacak hedeflerinin olması, öğrenici merkezli olması, biçim-işlev-anlam üçlüsünü kapsayacak şekilde gerçek dünya ile ilişkili olması ve doğrudan deneyimlere açık olması gerektiğini belirtmektedir. Bu ölçütlere çevrim içi görevlerin gerçek iş birliği ve etkileşimi teşvik etmesini de eklemektedir.

Araştırmacılar tarafindan çevrim içi dil öğretiminde kullanılabilecek görevlere ilişkin ölçütler incelendiğinde şu noktalarda ortaklıkların bulunduğu görülmektedir:

1. Görevler dil öğretiminin hedeflerine yönelik olmalıdır. Görevler dil öğretiminin başında belirlenen hedeflere ulaşılmasında bir araçtır. Bu nedenle hedeflerden ayrı olarak planlanması düşünülemez. Öğretimde görevler iletişimsel becerileri geliştirmek, iş birliğini sağlamak, topluluk bağı oluşturmak gibi hedeflerde kullanılabilir.

2. Görevler öğrenme için anlamlı ve zengin girdiler içermelidir. Her görevin dil öğretiminde bir anlamlı girdi kaynağı olduğu söylenebilir. Ancak her girdinin dil öğretimi açısından değeri aynı olmamaktadır. Bu noktada anlamlı girdilerin sunulması ve öğrenici tarafından işlenmesi gerekmektedir. Anlamlı girdi, kazandırılması gereken anlam veya yapıya ilişkin öğrenme firsatları içeren girdilerdir. Öğreticinin girdi sağlama konusunda seçici olması ancak bunu yaparken girdilerin özgün değerini azaltmaması gerekmektedir.

3. Görevler gerçek dünya ile ilişkili olmalıdır. Görevler, dil öğretiminde ortaya konulan yapıların öğreniciler tarafindan iletişimsel ve işlevsel amaçlarla kullanılmalarını sağlamalıdır. Bu bağlamda doğrudan dil bilgisi öğretimine yönelik bir görevin tasarlanması yerine bu bilginin kullanılabileceği gerçek dünyaya ilişkin bağlamın da verilmesi hedeflenmelidir.

4. Görevler yansıtıcı çıktılar içermelidir. Bir görev doğrudan deneyimler yoluyla öğrenmeyi sağlarken bunun öğrenicinin yaşamında da kullanılması ve öğreniciye olumlu bir etki bırakması hedeflenmelidir. $\mathrm{Bu}$ süreçte öğrenicilerin çevrim içi tartışmalara katılımı, yorumlar yazması ve video hazırlaması birer çıktı olarak ele alınacağı gibi onların öğrenimlerinde özerkliklerini güçlendirmeleri, ilgi ve güvenlerini artırmaları da birer çıktı olarak değerlendirilir.

5. Görevler iş birliği ve etkileşim firsatları barındırmalıdır. Görevler etkileşimi ve iş birliğini teşvik edecek şekilde planlanmalıdır. İş birlikli görevlerin gerçekleştirilmesinde öğrenicilerin anlam ve yapı üzerine müzakere etmeleri, bilgilerini tekrarlamaları ve akranlarından öğrenmeleri sağlanmalıdır. Bu noktada iş birlikli görevlerde öğreniciler arasındaki iletişim, onların destekleyici iskele inşa etmelerine ve kademeli olarak öğrenen özerkliğini geliştirmelerine yardımcı olacaktır.

6. Görevler öğrenicinin özelliklerine uygun olmalıdır. Öğrenicilerin ihtiyaçları ve istekleri ile görevler arasında doğrudan bir ilişki olmalıdır. Görevlerde öğrenicilerin dil yeterlikleri, teknolojik okuryazarlıkları, yaşadıkları çevre ve öğrenme tercihleri göz önünde bulundurulmalıdır. Görevlerin hazırlanmasında ve görevlerde öğreniciye biçilen rollerde esneklik ve çeşitlilik sağlanmalıdır. 


\section{Çevrim İçi İş Birlikli Görevlerde Teknolojinin Kullanımı}

Teknolojik araçların iş birlikli görevlerde kullanılması pek çok araştırmaya konu olmuştur (Tudini, 2003; Sotillo, 2006; Lund, 2008; Wang \& Chen, 2012). Sosyal mesafenin gerektiği, öğretimin uzaktan eğitim araçları ile sürdürüldüğü durumlarda ise görevlerin birlikte çalışmaya olanak tanıyan araçlara hızlı bir şekilde uyarlanması gerekmiştir. Çevrim içi iş birlikli görevler teknoloji ile dil becerilerinin, kültür ve dünya bilgisinin birlikte kullanılmasına yardımcı olur. Bu noktada teknolojik araçların etkin kullanımı görevin bir parçası olabileceği gibi, bu araçlar görevin gerçekleşmesine aracılık da edebilir. $\mathrm{Bu}$ nedenle öğretici ve öğrenicilerin dijital okuryazarlık düzeyi görevin hedeflerine ulaşmasında belirleyicidir. Öğreticilerin sahip olması gereken temel teknolojik yeterliklere bakıldığında (Hauck \& Stickler, 2006; Kessler 2006; Douglas, 2011; Sun, 2011) güncel yazılım ve uygulamaları takip etme, bunlar üzerinden içerik geliştirme, yazılım ve donanım kaynaklı temel sorunları gidermeyi bilme, kullanılan araçların güçlü ve zayıf yanlarını bilme, öğreniciye bu araçlar hakkında rehberlik etme ve günlük yaşamında da teknolojik araçları kullanabilme öne çıkmaktadır. Benzer şekilde öğrenicilerin de öğrenicilerden de günlük yaşamlarında teknolojik araçları kullanma yeterliğine ve bunları kullanmaya ilişkin olumlu bir tutuma sahip olmaları beklenmektedir.

Son (2010), öğretici ve öğrenenlerin kullanabilecekleri çevrim içi araçları on iki başlık altında sınıflandırmaktadır. Bunlar öğretim ve yönetim sistemleri, iletişim, gerçek ve sanal dünya, sosyal ağ, blog ve vikiler, sunum, kaynak paylaşımı, İnternet sitesi oluşturma, etkinlik üretme, arama, sözlük ve yardımcılar olarak sıralanmaktadır. İhtiyaç ve hedefler kullanılacak araçların birincil belirleyicisidir. Belirlenen araçlara göre görevler türetileceği gibi, hazır görevlerin de araçlara uyarlanması mümkündür. Görevler çok boyutlu, birçok aracın kullanıldığı, büyük bir proje olarak tasarlanabileceği gibi, daha dar kapsamlı ve kısa süreli olarak da tasarlanabilir. Her katılımcının katkıda bulunması, grup üyeleri ve gruplar arasında etkileşimin sağlanması iyi bir görev için şarttır. Yazının devamında çevrim içi dil öğretiminde küçük gruplara (4-5 kişi) yönelik iş birlikli görev önerileri yer almaktadır.

\section{Küçük Gruplar için İş Birlikli Görev Önerileri}

İş birlikli görevler öğrenicilerinin tamamını kapsadığı ve eşit katılımlı olduğu takdirde öğreticinin öngördüğü hedeflere ulaşabilir. Görevin yerine getirilmesinde öğrenicilerin birbirleri ile kurdukları iletişim ve öğreticinin dönütleri de sürecin bir parçasıdır. Kişiler arasındaki fiziki mesafenin getirdiği iletişim sınırlılıklarının aşılmasında video konferans programlarından yararlanılır. Bunun yanında katılımlı metin ve grafik üretmeye izin veren uygulamalara da başvurulabilir. Sürece daha fazla esneklik kazandırılmasında eş zamanlı etkileşimin yanında eş zamansız etkileşime de izin verilir.

Aşağıda çevrim içi ortamda Türkçe öğretimine yönelik küçük gruplar için iş birlikli görev önerileri yer almaktadır. Görevlere ilişkin kazanımlar ve hedefler Diller İçin Avrupa Ortak Başvuru Metni uyarınca belirtilmiştir. Görevler günlük internet kullanımı göz önünde bulundurularak tasarlanmıştır. Görevlerin tasarlanmasında öğrenicilerin birbirleri ile Türkçe sözcüklerin anlamlarını ve 
kullanılacak dil bilgisi kalıplarını müzakere etmeleri yani iş birlikli diyalog çerçevesinde etkileşime girmeleri amaçlanmıştır.

Tablo 1.

Internetten Hesapll Allşveriş

Düzey: A2

Beceriler: Konuşma, okuma ve yazma

Konuşma: Fazla çaba sarf etmeden basit, rutin bilgi alışverişinde bulunabilir. Sınırlı sayıdaki takip edici soruların üstesinden gelebilir.

Okuma: Listelerdeki belirli bilgilerin yerini bulabilir ve gerekli bilgiyi ayırt edebilir.

Yazma: Bir dizi basit tümleçleri ve cümleleri "ve", "ama", "çünkü" gibi basit bağlaçlar kullanarak yazabilir.

Araçlar: Skype/Zoom, Google belgeler ve Türkçe alışveriş siteleri (N11, Trendyol, Amazon, Gittigidiyor, Hepsiburada)

Grubu oluşturan öğrenicilerden alışveriş sitelerini inceleyip ihtiyacı ve bütçeyi göz önünde bulundurarak en uygun ürünü önermeleri istenir. Ürünün seçiminde öğrenicilerin ürüne ait fiyatları karşılaştırmaları, yorumlara bakmaları, ödeme seçenekleri ve gönderim süresini de değerlendirmeleri beklenmektedir. Öğreniciler bir video konferans programı yolu ile birbirleri ile iletişime geçer ve alışveriş sitesi üzerinden gerekli ürünü aramaya başlar. $\mathrm{Bu}$ aşamada öğreniciler yorumları okur, satıcının ve ürünün özelliklerini inceler, birbiri ile ilişkili sözcüklere bakar. Alınacak ürün belirlendiğinde, verilen kararın gerekçeleri Google belgelere yazılarak ortak bir metin oluşturulur ve öğreticiye gönderilir. Öğretici okuduğu ileti üzerinden ürün ile ilgili sözlü sorular sorarak öğrenicilerin gerekçelerini açıklamasını ister.

Tablo 1'de yer alan birinci görevde hava durumuna göre kıyafet satın almak, ev veya araba kiralamak, verilen karakter özelliklerine göre hediye seçmek gibi günlük internet kullanımına yönelik bir tema belirlenmiştir. Ayrıca bu görevde daha fazla dönüt sağlamak için öğrenicilerden gerçekleştirdikleri grup görüşmesinin kayıtlarını göndermeleri de istenebilir. Bu kayılar üzerinden dönütler sözlü ve yazılı olarak sağlanabilir.

Tablo 2.

Antalya'da Unutulmaz Tatil

Düzey: B1

Beceriler: Konuşma, dinleme, okuma ve yazma

Dinleme: Sorunlara çözüm olarak veya nereye gidilecek, ne yapılacak, bir olay nasıl düzenlenecek gibi pratik sorulara ait kendi fikirlerinin ve tepkilerinin anlaşılır olmasını sağlayabilir.

Konuşma: Gezi, konaklama, yeme ve alışveriş gibi günlük yaşamın genel özellikleriyle baş edebilir.

Okuma: Mektuplar, broşürler ve kısa resmî belgeler gibi günlük malzemelerdeki ilgili bilgiyi bulabilir ve anlayabilir.

Yazma: Önemli olduğunu düşündüğü noktaları anlaşılır bir biçimde aktaran, arkadaşlarına, hizmetlilere, öğretmenlere ve günlük hayatının bir parçası olan diğer insanlara derhal gerekmekte olan basit bilgileri ifade eden notlar yazabilir.

Araçlar: Skype/Zoom, Google belgeler, Türkçe otel ve tatil siteleri (Trivago, Tatilsepeti, Odamax)

Gruptaki öğrenicilere yapılan bir çekiliş sonucu Antalya'da on günlük konaklamayı içeren bir tatil ve on bin lira ikramiye kazandıkları söylenir. Öğrenicilerden bu on günü kapsayacak ve verilen ikramiyeyi aşmayacak bir tatil planlamaları istenir. Ulaşımın hava veya kara yolu ile nasıl gerçekleşeceği, kalınacak yerin seçimi ve gidilecek yerde hangi etkinliklerin yapılacağı ayrıntılı bir şekilde planlanır. Öğrenicilerden farklı başlıklar altında 
çeşitli tatil ve otel sitelerinden topladıkları bilgileri birbirleri ile paylaşmaları ve ortak bir seçime ulaşmaları beklenir. Hazırlanan tatil planı Google belgelerde oluşturacakları ortak bir sunumla öğreticiye açıklanır.

Tablo 2'de yer alan ikinci görevde öğrenicilerin İnternetteki tatil, tur ve otellere ait siteleri incelemeleri gerekmektedir. Birinci görevdeki gibi yine bütçe sınırı belirlenmiştir. Görev içinde belirli sınırlılıklara yer vermek öğrenicilerin verecekleri kararı müzakere etmeye ve görev üzerinde daha fazla düşünmeye yönlendirecektir. Farklı ve kapsamlı başlıklar içeren bu tür göreve öğretici de danışman rolü ile katılabilir. Öğreticinin sadece kendine danışılan noktalarda öğrenicileri desteklemesi ve anlama dönük ipuçları sunması önemlidir.

Tablo 3.

\section{Turizm Raporu}

Düzey: B2

Beceriler: Dinleme, konuşma, yazma ve az miktarda okuma

Dinleme: Dilsel olarak karmaşık olan konferansların, konuşmaların, raporların ve diğer biçimlerdeki akademik/profesyonel sunumların esaslarını takip edebilir.

Konuşma: Kendi düşünce ve fikirlerini net bir şekilde ifade edebilir, tartışma noktalarını ikna edici bir şekilde sunabilir ve karşıllk verebilir.

Okuma: Önemli ayrıntıları tespit ederek, uzun ve karmaşık metinleri hızlıca tarayabilir.

Yazma: Belirgin noktaları uygun vurgulama ve ilgili destekleyici ayrıntılarla, bir tartışmayı sistematik olarak geliştiren bir deneme ya da rapor yazabilir.

\begin{tabular}{l}
\hline Araçlar: Skype/Zoom ve Miro \\
\hline Öğrenicilerin bu görev kapsamında beyin firtınası ile belirli bir konu hakkında çok sayıda \\
düşünce üretmeleri ve bunlar üzerine birbirleri ile diyaloğa girmeleri hedeflenir. Üzerinde \\
çalışlacak konu öğretici tarafindan belirlenebileceği gibi öğreniciler de konu önerisinde \\
bulunabilir. Öğrenicilerden bakanlığa sunulması için turizmin olumlu ve olumsuz yanları \\
üzerine bir rapor hazırlamaları istenir. Öne sürülen düşünceler Miro uygulaması üzerinde \\
oluşturulacak panoya yazılır. Öğretici düşüncelerin panoya yazılması sırasında öğrenicilere \\
anlık dönütler verebilir. Düşünceler panoya aktarıldıktan sonra öğreniciler birbirlerine \\
danışarak panodaki düşünceleri gruplandırır ve raporun ana başlıklarını belirler. Hazırlanan \\
raporun üzerinde uzlaşllan son hâli öğreticiye sunulur.
\end{tabular}

Tablo 3'te yer alan üçüncü görevde öğrenicilerin bir konunun olumlu ve olumsuz yönlerini serbest bir şekilde hedef dilde paylaşması ve paylaşılan düşünceler üzerinde diğer öğreniciler ile değerlendirmesi beklenmektedir. Görüşlerin paylaşılmasında beyin firtınası tekniğine başvurulurken görevlerin yazılı belge hâline getirilmesinde iş birlikli yazmaya başvurulur. Öğretici görev sürecinde panoya aktarılan düşüncelerin dile uygunluğuna ilişkin anlık dönüt verebilir. Bunun yanında öğreniciler arasındaki müzakerelerde de dinleyici olarak sözlü dönütlerde bulunabilir. Görev için konunun düşünce üretimine açık olması ve öğrenicilerin sahip oldukları söz dağarcığı da göz önünde bulundurulmalıdır.

Tablo 4.

Nefis Yemek Tarifleri Instagram Sayfast

Düzey: A1

Beceriler: Konuşma, dinleme, yazma

Konuşma: Kendisine dikkatlice ve yavaşça yönlendirilen soruları ve yönergeleri anlayabilir ve kısa basit yönlendirmeleri takip edebilir

Dinleme: Kendisi, tanıdığı kişiler ve çevresindeki nesnelerle ilgili çok basit kalıpları anlayabilir. 


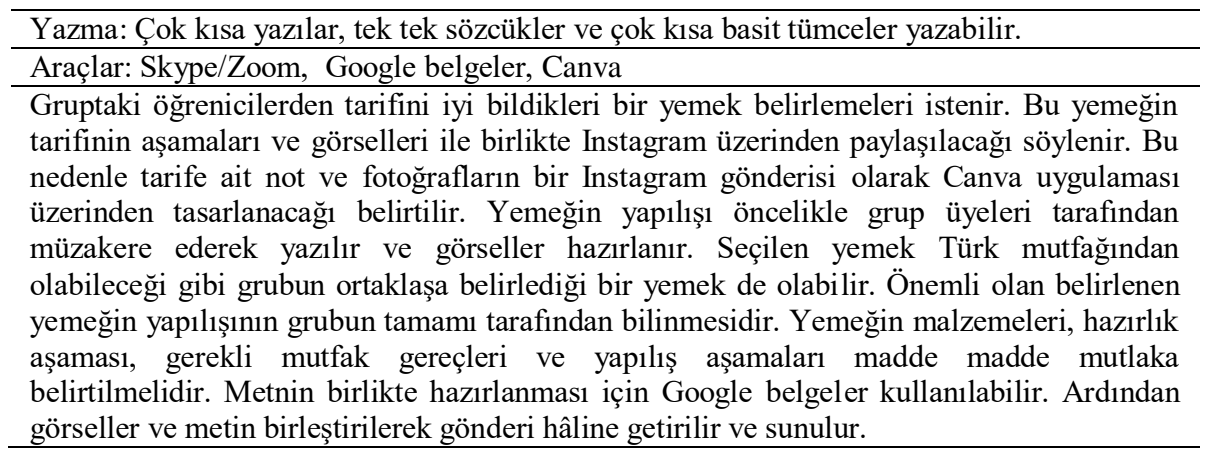

Tablo 4'te yer alan dördüncü görev içerisinde öğrenicilerin birlikte bir işin bileşenlerini ve yapılış aşamalarını sırasıyla yazmaları amaçlanmaktadır. $\mathrm{Bu}$ kapsamda görev için yemek tarifi yazmaları istenmiştir. Ancak görev günlük hayatta yapılan bir işin nasıl gerçekleştirildiğine ilişkin olarak (örneğin bir kullanma kılavuzu hazırlama) da tasarlanabilir. Görevin gerçekleştirilmesinde öğrenicilerin ortak metin üretmesi amaçlanmaktadır. Özellikle temel düzey öğreniciler için uygulanabilir bir görev olarak düşünülebilir.

Tablo 5.

Meslek Kataloğu

Düzey: A2

Beceriler: Yazma, dinleme, okuma ve konuşma

Dinleme: Yavaşça ve anlaşıılır biçimde anlatılan tahmin edilebilen günlük hususlar hakkındaki kısa, kayıt edilmiş pasajları anlayabilir ve gerekli bilgileri çıkartabilir.

Konuşma: Fazla çaba sarf etmeden basit, rutin bilgi alışverişinde bulunabilir. Sınırlı sayıdaki takip edici soruların üstesinden gelebilir.

Okuma: Çok fazla tekerrür eden günlük veya iş ile ilgili dilden oluşan somut türdeki bildik hususlardaki kısa, basit metinleri anlayabilir.

Yazma: Kendi çevresinin her günkü yönlerini, bir iş ya da çalışma deneyimini birbirine bağlı cümlelerle yazabilir

Araçlar: Skype/Zoom ve Google belgeler

$\mathrm{Bu}$ görevde her biri iki ögreniciden oluşan iki grubun kısa paragraf yazması ve bu paragrafın dikte çalışması olarak kullanılması amaçlanır. Öğretici ilk olarak meslekleri tanıtır. Bunun ardından her grubun bir meslek seçmesini ve bu mesleğe ait tanıtıcı bir paragraf yazmalarını ister. Paragrafın yazımında grup üyelerinin ortak katılımı şarttır. Paragrafların yazımının ardından bir öğrenici metni sesli olarak okur ve diğer gruptaki öğreniciler dinledikleri metni yazar. Bu işlem diğer grup için de tekrarlanır. Diktenin ardından öğreniciler birbirlerine metinleri gösterirler ve hem metnin hem de yazılanların üzerine değerlendirme yaparlar. Öğretici de değerlendirme aşamasına dönütleri ile katılır.

Tablo 5'te yer alan ve özellikle temel düzeydeki öğreniciler için uygun olan beşinci görev ile hem öğrenicilerin birlikte metin yazmaları hem birbirleri ile yazdıkları metinler bağlamında sözlü etkileşime girmeleri amaçlanmıştır. Öğreniciler birbirlerinin hatalarını düzeltirken, gerekli noktalarda öğreticiye danışabilir. Konu öğrenicilerin ilgi ve düzeylerine göre değiştirilerek hemen her konuya uyarlanabilir.

Önerilen bu görevler çeşitli konular ve düzeylere göre çevrim içi ortamda Türkçe öğrenenler için yeniden tasarlanabilir ve zenginleştirilebilir. Görevlerin çok boyutlu 
hâle getirilmesinde kullanılacak teknik araçların ve öğrenicilerin bunları kullanma becerilerinin etkisi de hesaba katılmalıdır. Her görev aynı zamanda öğrenicilerin bilişim becerilerini kullanmayı da zorunlu kılmaktadır. Öğreticiler bu noktada öğrenicilere rehberlik etmeyi ihmal etmemelidir.

\section{Kültür Öğretimine Yönelik İş Birlikli Görev Önerileri}

Dilin konuşulduğu ülkeye ve o ülkenin kültürüne ilişkin bilgiler de çevrim içi iş birlikli görevler üzerinden öğrenicilere sunulabilir. Bu amaçla Google haritalar Türkiye'deki şehirlerin sokak görüntülerini içermektedir. Pek çok müzenin sanal tur seçenekleri bulunmaktadır. Pek çok Türk sanatçı eş zamanlı ve eş zamansız olarak çevrim içi ortamda sanal sergi, konser ve söyleşiler gerçekleştirmektedir. Kültür ve ülke bilgisinin harmanlandığı görevler çerçevesinde öğrenicilerin bu uygulamalardan faydalanması sağlanabilir.

Tablo 6'da yer alan altıncı görevde öğrenicilerin Google haritalarda yer alan metin, fotoğraf ve sokak görüntülerinden yararlanarak bir şehir turu planlaması gerekmektedir. Öğrenicilerin kararlaştırdıkları veya ziyaret etmek istedikleri mekânlar hakkında Türkçe bilgi toplamaları ve daha önce o mekânları ziyaret edenlerin yorumlarını okuyarak izlenim edinmeleri hedeflenmektedir. Ayrıca görev, öğrenicilerin düzeyine göre farklı şekillerde değiştirilerek sunulabilir. Örneğin temel düzey öğrenicilerden şehir turu yerine Google haritalardan bir şehre ait bir veya birkaç yer, yapı ve eseri seçip tanıtıcı bir yazı yazmaları veya sözlü sunum hazırlamaları istenebilir.

Tablo 6.

Amasya Şehir Turu

Düzey: A2, B1, B2

Hedef: Diğer ülkelerdeki bireylerin düşünce yapılarının, kültürel miraslarının yaşam biçimlerinin daha geniş ve ayrıntılı bir şekilde anlayabilir.

Araçlar: Skype/Zoom, Google haritalar, Vikipedi ve Google belgeler

Gruptaki öğrenicilerden Amasya şehrini ziyaret edecek bir turist kafilesi için yarım günlük bir şehir turu hazırlamaları istenir. Görülmesi gereken yerlere yürüyerek gidilecektir. Bu nedenle ziyaret noktaları belirli bir sıra ve mesafe dâhilinde belirlenmelidir. Şehir turunun planlanmasında Google haritalar uygulamasından Amasya şehrinin haritasına ulaşır. Mekân ve anttlara ait diğer ziyaretçilerin yorum ve derecelendirmeleri incelenebilir. Turda yer alacak noktalar hakkında bilgi almak için Vikipedi sayfalarından da yararlanılabilir. Öğreniciler hazırladıkları şehir turunu resim, harita ve fotoğraflar ile zenginleştirerek Google belgeler üzerinden katılımlı bir şekilde sunum hâline getirir.

Kültür ve turizme yönelik faaliyet gösteren kurumlara ait müzeler çeşitli sanal tur uygulamaları içermektedir. Sanal tur özellikle Türkiye’ye gelme olanağı bulunmayan öğrenicilerin ülkenin sahip olduğu kültür ve sanat varlıklarını çevrim içi ortamda da olsa tanıma firsatı vermektedir. $\mathrm{Bu}$ bağlamda sanal tur uygulamalarının kullanılabileceği görevler tasarlanabilir. Öğrenicilerin ilgilerine göre bir müze, sergi veya ören yeri seçilebilir ve sanal tur üzerinden bir gezi gerçekleştirilebilir. Ören yerleri, Anıtkabir ve Deniz Müzesi sanal tur olanağına sahip yerlerden bazılarıdır. Tablo 7'de yer alan yedinci görevde de Ankara Resim ve Heykel Müzesi sitesinde yer alan sanal tur uygulamasının kullanımını içeren bir etkinlik planlanmıştır. 
Tablo 7.

Müzede Bir Gün

Düzey: A1, A2, B1, B2

Hedef: Diğer ülkelerdeki bireylerin düşünce yapılarının, kültürel miraslarının yaşam biçimlerinin daha geniş ve ayrıntılı bir şekilde anlayabilir.

Araçlar: Skype/Zoom, Vikipedi ve Google belgeler

Bu görev kapsamında ögrenicilerin Ankara Resim ve Heykel Müzesi internet sitesinde yer alan sanal tur uygulamasını kullanmaları gerekmektedir. Öğrenicilerden öncelikle sanal tur ile müzede yer alan eserleri inceleyip ilgilerini çekenleri not almaları istenir. Öğreniciler not aldıkları eserlerden birini (veya ikisini) oylama veya aralarında anlaşarak seçer. Daha sonra seçtikleri eseri tanıtıcı bir yazı veya konuşma hazırlar. Hazırlanan metin eser ve eserin yaratıcısı ile ilgili genel bilgilerin yanında eserin öğreniciler üzerinde bıraktı̆g izlenimi de içermelidir (eserin teması, konusu, renkleri, sevilen ve sevilmeyen tarafları, öğrenicinin bu esere sahip olma isteği). Ayrıca bu görev öğreticinin öğrenicilere sanal turdan önce belirlediği bir sanatçı ve eserin bulunması şeklinde (eserin genel tarifi, sanatçısı hakkında bilgiler vb.) de düzenlenebilir.

Kültürün öğretilmesine yönelik görevler de diğer iş birlikli görevler gibi öğreniciler arasında diyaloğun ve etkileşimin gerçekleşmesi için firsatlar sağlamalıdır. $\mathrm{Bu}$ noktada görevlerin hazırlanması, sanal tur etkinliğinin gerçekleşmesi gibi bölümlerde öğretici yol gösterici ve yönlendirici bir rol oynayabilir.

\section{Sonuç ve Öneriler}

Geleneksel Görevler Bialystok (1978), Long (1985) ve Krashen'in (1987) dil öğretiminde girdi, çıktı, etkileşim ve dönüt gibi dil öğretimi için hayati olarak gördükleri süreçlere zemin oluşturmaktadır. İletişim düzeneklerinin çeşitlenmesi ve yüz yüze eğitimin yapılamadığı durumların yarattığı yeni koşullar görevlerin çevrim içi ortamda kullanılmasının önünü açmıştır. Bu kapsamda makalede öncelikle Doughty ve Long (2003), Gonzales Lloret (2020), Hampel (2010) ve Wang'ın (2007) çevrim içi dil öğretiminde kullanılacak görevler için öne sürdükleri kıstaslar incelenerek bunlar üzerinden altı ölçüt belirlenmiştir. Bu ölçütler hedeflerine yönelik olma, öğrenme için anlamlı ve zengin girdiler içerme, gerçek dünya ile ilişkili olma, yansıtıcı çıktılar içerme, iş birliği ve etkileşim firsatları barındırma ve öğrenicinin özelliklerine uygun olma şeklinde sıralanmaktadır.

Ölçütlere göre tasarlanan görevler ile öğrenicilerin birbirleri ile konuşmaları, birbirlerini dinlemeleri ve birlikte yazmaları amaçlanmıştır. Swain (2000) hedef dilde iş birlikli diyaloglar üretilmesinin öğrenicilerin birbirlerinin dil üretimlerini denetlemelerine ve desteklemelerine yardımcı olacağını belirtmektedir. Makale kapsamında önerilen etkinliklerde de öğrenicilerin günlük internet kullanımlarından aşina oldukları konular için hedef dili kullanacakları ve bunu yaparken diğer öğreniciler ile içerik ve yapı üzerinde müzakere edecekleri öngörülmüştür. Buna göre grup üyelerinin görev kapsamında İnternet üzerinden topladığı veriler ortaya konulacak, üyeler tarafindan değerlendirilecek ve görev için uygun bir forma sokulacaktır. Görevin başarıya ulaşmasında grup içi katılımın dengeli olması ve öğrenicilerin ilgisi gereklidir. Bunun yanında kültürün ve ülke bilgisinin öğretiminde görevlerin yanında öğrenicilerin tandem sitelerinden ana dili konuşucuları ile iletişim kurmaları kültürler arası etkileşim olanağı da sağlayacağından yararlı 
olabilir. Tandem siteleri aynı zamanda hedef dilde iletişimi gerektirdiğinden öğrenilenlerin sınıf dışında da kullanılmasına yardımcı olacaktır.

Chapelle (2001) 21. yüzyılda teknolojinin bir şekilde dil öğretiminin bir parçası olacağına dikkat çekmektedir. $\mathrm{Bu}$ bağlamda öğreticiler görevler ile teknolojinin ilişkisini her zaman göz önünde bulundurmalıdır. Sınıf ortamındaki iş birlikli görevlerden farklı olarak öğrenicilerin teknolojik donanım ve yazılımları etkin bir şekilde kullanması görevin başarıya ulaşması için önemlidir. Öğreticiler her şeyden önce görevlerin gerçekleşmesinin en temel şartının iyi bir İnternet ağı ve yeterli teknik donanıma sahip olmaktan geçtiğini bilmelidir. Bunun ardından öğrenicilerin donanım ve yazılımı kullanım bilgisini de kapsayan yeterli dijital okuryazarlığa sahip olması gereklidir. Öğreniciler arasında dijital okuryazarlığa ilişkin farkın derin olmamasına dikkat edilmelidir. Bu noktada öğretici yeri geldiğinde dil öğretmeni kimliğini bir kenara bırakarak öğrenicilerin ihtiyaç duyduğu teknik desteği vermelidir. Gonzales Lloret (2020) öğretime başlamadan önce hedef kitlenin dijital becerilerini ortaya koyacak bir ihtiyaç analizinin yapılmasını önermektedir. Dil öğretimine başlamadan önce öğrenicilerin dijital okuryazarlık durumlarının bilinmesi görevlerde kullanılması düşünülen yazılım ve uygulamaların gözden geçirilmesini gerektirebilir veya kısa bir uyum eğitimi verilerek temel gereklilikler (Örneğin Google belgelerin verimli kullanımı için bu sitenin e-posta adresine sahip olma gibi) sağlanabilir. İleriye dönük olarak Türkçenin çevrim içi öğretimi açısından iş birlikli görevler ve teknik donanım ile ilgili öğretici ve öğrenicilere yönelik ihtiyaç analizi çalışmalarının yapılması alan açısından yol gösterici olacaktır.

\section{Etik Kurul Beyanı}

Bu makale kuramsal bir makaledir. Katılımcıların yer aldığı herhangi bir uygulama ve deney çalışması içermemektedir. Bu nedenle etik kurul onayı için başvuruda bulunulmamıştır. Makalede bilimsel, etik ve alıntı kurallarına uyulmuş; bilimsel gerçekler üzerinde herhangi bir çarpıtma yapılmamıştır. Etik ihlal sorumluluğunun yazara ait olduğu ve bu makalenin daha önce yayınlanmamış ve paylaşılmamış olduğu sorumlu yazar tarafindan taahhüt edilmiştir.

\section{Kaynakça}

Başkaya, K., \& Tursunovic, M. (2017). Yabancı dil olarak Türkçe öğretiminde işbirlikli ögrenme ve Padlet. Aydın Tömer Dil Dergisi, 2(2), 79-96.

Bialystok, E. (1978). A theoretical model of second language learning. Language Learning, 28(1), 69-83.

Bölükbaş, F. (2014). JIGSAW-IV tekniğinin yabancı öğrencilerin Türkçedeki temel zamanları öğrenmeleri üzerindeki etkisi. Uluslararası Türkçe Edebiyat Kültür Eğitim Dergisi, 3(3), 196-209.

Chapelle, C. (2001). Computer applications in second language acquisition: Foundations for teaching, testing and research. Cambridge University Press.

Cook, V. (2001). Second language learning and language teaching. Arnold.

Çubukçu, Z. (2012). İşbirlikli öğrenme. B. Oral (Ed.), Öğrenme ve öğretme kuram ve yaklaşımları içinde (s. 509-526). Pegem Akademi. 
Doughty, C., \& Long, M. (2003). Optimal psycholinguistic environments for distance foreign language learning. Language Learning \& Technology, 7(3), 50-80.

Douglas, J. A. (2011). Competency for quality online teaching [Unpublished doctoral dissertation]. University of Virginia.

Ekinci, Z. (2018). İşbirlikli yazma etkinliklerinin Türkçeyi yabancı dil olarak öğrenenlerin yazma becerilerini geliştirmeye etkisi [Yayımlanmamış yüksek lisans tezi]. Bolu Abant İzzet Baysal Üniversitesi.

Ellis, R. (2003). Task-based language learning and teaching. Oxford University Press.

Gibbons, P. (2015). Scaffolding language, scaffolding learning: Teaching English language learners in the mainstream classroom. Heinemann.

Gonzales Lloret, M. (2020). Collaborative tasks for online language teaching. Foreign Language Annals, 53, 260-269.

Gruba, P. (2004). Designing tasks for online collaborative language learning. Prospect, 19(2), $72-81$.

Hampel, R. (2010). Task design for a vital learning environment in a distance language course. In M. Thomas, \& H. Reinders (Eds.), Task-based language learning and teaching with technology (pp. 131-153). Continuum Publishing Group.

Hauck, M., \& Stickler, U. (2006). What does it take to teach online? CALICO Journal, 23(3), 463-475.

Kessler, G. (2006). Assessing CALL teacher training: What are we doing and what we could do better? In P. Hubbard, \& M. Levy (Eds.), Teacher education in CALL (pp. 23-44). John Benjamins.

Krashen, S. (1987). Principles and practice in second language acquisition. Prentice Hall.

Larsen Freeman, D. (2003). Teaching and principles in language teaching. Oxford University Press.

Lempinen, E. (2020, May 27). The pandemic could open a door to new technology -and dramatic innovation- in education. Berkeley News. https://news.berkeley.edu/2020/05/27/the-pandemic-could-open-a-door-to-newtechnology-and-dramatic-innovation-in-education

Long, M. N. (1985). Input and SLA theory. In S. M. Gass, \& C. G. Madden (Eds.), Input in second language acquisition (pp. 377-393). Newbury House Publishers.

Lund, A. (2008). Wikis: A collective approach to language production. ReCALL, 20(1), 3554.

MEB Talim ve Terbiye Kurulu Başkanlığı. (2009). Diller için Avrupa ortak başvuru metni ögrenme-ögretme-değerlendirme. Talim Terbiye Kurulu Başkanlığı Yayınları.

Nunan, D. (1989). Designing tasks for the communicative classroom. Cambridge University Press.

Oxford, R. (2006). Task-based language teaching and learning: An overview. Asian EFL Journal, 8(3), 94-121.

Riazi, M., \& Rezaii, M. (2010). Teacher and peer-scaffolding behaviors: Effects on EFL students' writing improvement. In A. Feryok (Ed.), CLESOL 2010: Proceedings of the 12th national conference for community languages and ESOL (pp. 55-63). TESOLNZ. 
Richards, J. C., \& Rodgers T. S. (2002). Approaches and methods in language teaching. Cambridge University Press.

Son, J. B. (2010, November 25). Online tools for language teaching. http://drjbson.com/projects/tools

Sotillo, S. M. (2006). Using instant messaging for collaborative learning: A case study. Innovate: Journal of Online Education, 2(3), 1-9.

Sun, S. Y. H. (2011). Online language teaching: The pedagogical challenges. Knowledge Management \& E-learning: An International Journal, 3(3), 428-447.

Swain, M. (2000). The output hypothesis and beyond: Mediating acquisition through collaborative dialogue. In J. P. Lantolf (Ed.), Sociocultural theory and second language learning (pp.97-114). Oxford University Press.

Swain, M., \& Lapkin, S. (2002). Talking it through: Two French immersion learners' response to reformulation. International Journal of Educational Research, 37, 285-304.

Tavakkoli, H. (2012). A dictionary of language acquisition a comprehensive overview of key terms in first and second language acquisition. Rahnama Press.

Tudini, V. (2003). Using native speakers in chat. Language Learning and Technology, 7(3), 141-159.

Varışoğlu, B. (2013). Türkçenin yabancı dil olarak öğretiminde birleştirilmiş iş birlikli okuma ve kompozisyon tekniğinin etkileri [Yayımlanmamış doktora tezi]. Atatürk Üniversitesi.

Vygostky, L. S. (1998). Düşünce ve dil. Toplumsal Dönüşüm Yayınları.

Wang, Y. (2007). Task design in videoconferencing-supported distance language learning. CALICO Journal, 24(3), 591-630.

Wang, Y., \& Chen, N. (2012). The collaborative language learning attributes of cyber face-toface interaction: the perspectives of the learner. Interactive Learning Environments, 20(4), 311-330. doi:10.1080/10494821003769081

Watanabe, Y., \& Swain, M. (2007). Effects of proficiency differences and patterns of pair interaction on second language learning: Collaborative dialogue between adult ESL learners. Language Teaching Research, 11, 121-42.

Wong, A. (2020, October 5). How can students learn online if they don't know the language? This city tackled the issue. The Seattle Times. https://www.seattletimes.com/educationlab/how-can-students-learn-online-if-they-dont-know-the-language-this-city-tackled-theissue

\section{Extended Abstract}

Traditional language teaching programs faced the danger of being interrupted and to some extent completely halted due to the global epidemic that started to be seen at the beginning of 2020 and made its impact felt all over the world. To overcome this, urgently, the teaching was quickly transferred to an online environment, and the academic semester was completed somehow. During this period, tutors had to use and manage many online materials more intensively than in the past. Tutors searched for a variety of materials and applications to turn them into inputs. In this article, as one of these quests, collaborative tasks that can be applied online are emphasized and some task suggestions are given. 
Approaches based on collaboration in language teaching aim to enable learners to learn from each other in a group. Teachers also have a role in the process together with the group. Collaborative learning is important in terms of increasing the frequency and diversity of target language applications through different types of interaction, facilitating the acquisition of the language on the basis of interaction, having the opportunity to integrate the language with content-based education, including a wide variety of curriculum materials, and serving as a resource for not only teachers but also learners.

Collaborative dialogue evaluated within this approach is defined as a dialogue in which learners are engaged in problem-solving and creating knowledge. These dialogues produced by the learners while interacting with each other enable them to learn new information about language from each other and to repeat what they know. Through dialogues, learners reconstruct meaning primarily through speaking and listening skills.

In this context, it is thought that collaborative tasks can be used for learners to be a part of a meaningful and supportive dialogue with their peers and teachers. Swain (2000) defines collaborative tasks as a step that starts to work together, to produce and thinking about the format and content in the target language. In this context, collaborative tasks will encourage students to develop a common sense of responsibility and ownership over the production of the product. Tasks enable the language to be acquired by the learners through operating the processes of interacting and negotiating purposefully. In this respect, the tasks provide a basis for meaningful interaction between two or more participants.

In this context, firstly, the criteria put forward by Doughty and Long (2003), Gonzales Lloret (2020), Hampel (2010) and, Wang (2007) for the tasks to be used in online language teaching were examined and the following six criteria were determined.

1. Tasks should be geared towards the goals of language teaching. Tasks are a means of achieving the goals set at the beginning of language teaching.

2. Tasks should contain meaningful and rich input for learning. It can be said that every task is a meaningful input source in language teaching. The tutor should be selective in providing inputs but should not reduce the original value of the inputs in doing so.

3. Tasks should be related to the real world. Tasks should ensure that the structures introduced in language teaching are used by learners for communicative and functional purposes.

4. Tasks should include reflective outputs. While a task enables learning through direct experiences, it should be aimed to use it in the life of the learner and to have a positive effect on the learner.

5. Tasks should be planned in a way that encourages interaction and collaboration. In the performance of collaborative tasks, learners should be enabled to negotiate on meaning and structure, repeat their knowledge, and learn from their peers. 
6. The tasks should be appropriate to the learner's characteristics. There should be a direct relationship between the learners' needs and desires and tasks.

In this article, it is aimed for learners to talk to each other, listen to each other, and write together with the tasks designed according to the criteria. Swain (2000) states that producing collaborative dialogues in the target language will help learners control and support each other's language production. In the activities suggested within the scope of the article, it was predicted that the learners will use the target language for the topics they are familiar with from their daily internet use, and while doing this, they will negotiate with other learners on the content and structure.

Collaborative tasks can achieve the goals set by the instructor if they include all of their learners and are the students are equally involved. Especially in the performance of the task in small groups, the communication between the learners and the instructor's feedback is also part of the process. Video conference programs are used to overcome the communication limitations caused by the physical distance between the individuals. Also, applications that allow the production of text and graphics with participation can be applied.

In addition to these, information about the country where the language is spoken and the culture of that country can be presented to learners through online collaborative tasks. To that end, Google maps include street views of cities in Turkey. Many Turkish artists perform online exhibitions, concerts, and talks simultaneously and asynchronously. It can be ensured that learners benefit from these applications within the framework of the tasks in which culture and country knowledge are blended.

The informatics competencies of the trainers and learners come to the fore in the implementation of collaborative tasks online. First of all, trainers should consider how to use the development of information technologies more effectively and how they will get high-level efficiency from it.

Tutors should always consider the relationship between tasks and technology. The most basic condition for the fulfillment of the tasks is to have a good Internet network and sufficient technical equipment. Next, learners must have sufficient digital literacy, including hardware and software usage knowledge. At this point, the teacher should give the technical support that the learners need by leaving aside his identity as a language teacher when needed. 